http://jmscr.igmpublication.org/home/

ISSN (e)-2347-176x ISSN (p) 2455-0450

crossref DOI: https://dx.doi.org/10.18535/jmscr/v8i12.28

Journal Of Medical Science And Clinical Research

IGM Publication

An Official Publication of IGM Publication

\title{
Study of Paediatric Dermatology Consultations during COVID-19 Lockdown
}

\begin{abstract}
Authors
Dhaarna Wadhwa, Sushruta Kathuria*, Niti Khunger

Department of Dermatology and Sexually Transmitted Diseases, Vardhman Mahavir Medical College and Safdarjung Hospital, New Delhi-110023, India

*Corresponding Author

Sushruta Kathuria

Department of Dermatology and Sexually Transmitted Diseases, Vardhman Mahavir Medical College and Safdarjung Hospital, New Delhi-110023, India

Abstract
A social lockdown was enforced by Indian government, restricting all non-essential travel, to combat
coronavirus disease 2019 (COVID-19) pandemic. We present a retrospective analysis on the data of
children $\leq 18$ years who presented to the dermatology outpatient department in a tertiary care hospital
during lockdown period. Out of 36 children, $50 \%$ had pruritic skin diseases, $5.5 \%$ had true
dermatological emergencies and $44.4 \%$ had nonpruritic, non-emergency conditions. Majority of these
could have been avoided and teleconsultation would have sufficed.
Keywords: Health care delivery, Coronavirus Infections, Paediatric dermatology.
\end{abstract}

Social lockdown was enforced by Indian government for a period of 68 days starting $25^{\text {th }}$ March 2020 to combat coronavirus disease 2019 (COVID-19) pandemic in the second most populous country in the world (population of 1.38 billion), with a purpose to restrict physical contact by prohibiting all travel that was not essential. Only people providing emergency services such as medical care, food and general security were allowed. ${ }^{[1]}$ The outpatient departments (OPD's) and elective procedures were suspended in most hospitals, however, ours being a tertiary care hospital, the OPD's were functional. The purpose of this study was to analyse the dermatological conditions for which children sought treatment during the lockdown.
A retrospective analysis was performed on the data of children $\leq 18$ years attending dermatology OPD in a tertiary care hospital (also catering to COVID-19 patients), for a standard face to face consultation during the lockdown. All patients were screened for symptoms suggestive of COVID-19 such as fever, cough, breathlessness and were referred to fever clinic if found positive.

A total of 539 patients attended dermatology OPD, out of which 36 (6.67\%) were $\leq 18$ years. The age ranged between 3 months to 18 years. Mean age was $13.75 \pm 4.79$ years. There were 23 males (63.8\%) and 13 females (36.2\%). These included one infant $(<1$ year), ten children $(1-12$ years) and 25 adolescents (13-18 years). Their clinical profile is depicted in Table 1. All these 
were new OPD registrations presenting with fresh complaints. The paediatric patients were accompanied by at least one guardian and none had signs and symptoms suggestive of COVID19. Fifteen patients (41.7\%) presented with infections, seven (19.4\%) had dermatitis and three $(8.3 \%)$ had urticaria. Two patients (5.5\%) presented with true dermatological emergencies: drug reaction and pemphigus vulgaris. Nine patients $(25 \%)$ had non-emergency, non-infectious conditions like acne, chronic telogen effluvium, hirsutism, acanthosis nigricans, keratosis pilaris, lichen nitidus and psoriasis vulgaris. Pruritus was presenting complaint in $18(50 \%)$ patients of scabies, tinea, intertrigo, urticaria, and dermatitis.

The average OPD attendance decreased from 616 patients/day $(28 \%$ paediatric cases) before lockdown to eight patients/day due to strict lockdown enforcement. Pruritic conditions (50\%) constituted the most common presentation. True dermatological emergencies $(5.5 \%)$ were few. The
$16(44.4 \%)$ patients presenting with nonpruritic, non-emergency problems causing some cosmetic disfigurement, illustrates how anything deviating from normal in children and adolescents is a grave concern for parents and hence becomes an emergency for them to visit a dermatologist. Infections were common in children (41.7\%) owing to their tendency to play together, overcrowding and hot and humid climate. The higher number of older children who presented, was probably because parents felt more comfortable in getting them to the hospital wearing a mask. Compared to previous studies in the literature, the paediatric consultations in our study were lesser during the pandemic and no patient presented with cutaneous signs or symptoms of COVID-19. ${ }^{[2]}$

For a vast majority of paediatric patients, teleconsultation would have sufficed in a situation which needed strict social lockdown, avoiding travel and exposure to COVID-19. ${ }^{[3]}$

Table 1: Clinical profile of children presenting to dermatology outpatient department during lockdown period to combat COVID-19 pandemic

\begin{tabular}{|c|c|c|}
\hline $\begin{array}{l}\text { True emergencies } \\
\text { (number of patients) }\end{array}$ & $\begin{array}{l}\text { Pruritic conditions } \\
\text { (number of patients) }\end{array}$ & $\begin{array}{c}\text { Non-emergency, } \\
\text { nonpruritic conditions } \\
\text { (number of patients) }\end{array}$ \\
\hline \multicolumn{3}{|l|}{ Infants (<1year) } \\
\hline & Atopic dermatitis (1) & \\
\hline \multicolumn{3}{|l|}{ Childhood (1-12 years) } \\
\hline \multirow[t]{5}{*}{ Pemphigus vulgaris (1) } & Scabies (2) & Acanthosis nigricans (1) \\
\hline & Urticaria (1) & Folliculitis (1) \\
\hline & Atopic dermatitis (1) & Verruca vulgaris (1) \\
\hline & & Keratosis pilaris (1) \\
\hline & & Molluscum contagiosum (1) \\
\hline \multicolumn{3}{|c|}{ Adolescents (13-18years) } \\
\hline \multirow[t]{7}{*}{ Drug reaction $(1)$} & Urticaria $(2)$ & Lichen nitidus (1) \\
\hline & Seborrheic dermatitis (3) & Telogen effluvium (1) \\
\hline & Scabies (4) & Herpes zoster (2) \\
\hline & Atopic dermatitis (1) & Acne vulgaris (3) \\
\hline & Intertrigo (1) & Hirsutism (1) \\
\hline & Tinea cruris $(1)$ & Folliculitis (2) \\
\hline & Irritant contact dermatitis (1) & Psoriasis vulgaris (1) \\
\hline
\end{tabular}


Source(s) of Support: None

Conflicting Interest: None

Acknowledgement: None

\section{References}

1. Paital B, Das K, Parida SK. Inter nation social lockdown versus medical care against COVID-19, a mild environmental insight with special reference to India. Sci Total Environ.2020;728:138914.

2. Temiz SA, Dursun R, Daye M, Ataseven A Evaluation of dermatology consultations in the era of COVID-19 [published online ahead of print, 2020 May 22]. Dermatol Ther. 2020;e13642.

3. Available from: https://www.mohfw.gov.in/pdf/Telemedici ne.pdf. [Last accessed on 2020 July 6]. 